\title{
Using applied pressure to guide materials design: a neutron diffraction study of $\mathrm{La}_{2} \mathrm{NiO}_{4+\delta}$ and $\mathrm{Pr}_{2} \mathrm{NiO}_{4+\delta}$
}

\author{
Craig L. Bull, Christopher J. Ridley and \\ Helen Y. Playford
}

\section{Published version information}

Citation: CL Bull, CJ Ridley and HY Playford. "Using applied pressure to guide materials design: a neutron diffraction study of $\mathrm{La}_{2} \mathrm{NiO}_{4+\delta}$ and $\mathrm{Pr}_{2} \mathrm{NiO}_{4+\delta}$." Dalton Transactions, vol. 49, no. 30 (2020): 10631-10637.

DOI: $\underline{10.1039 / D O D T 02155 E}$

This version is made available in accordance with publisher policies. Please cite only the published version using the reference above. This is the citation assigned by the publisher at the time of issuing the AAM. Please check the publisher's website for any updates. 


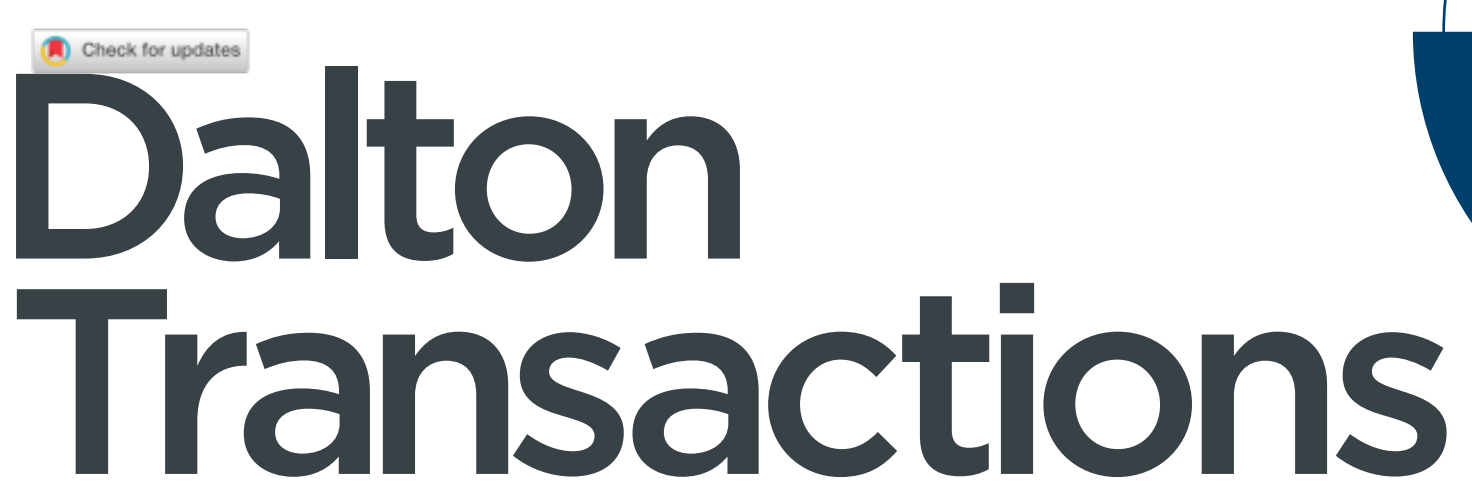

An international journal of inorganic chemistry

\section{Accepted Manuscript}

This article can be cited before page numbers have been issued, to do this please use: C. L. Bull, C. J.

Ridley and H. Y. Playford, Dalton Trans., 2020, DOI: 10.1039/D0DT02155E.
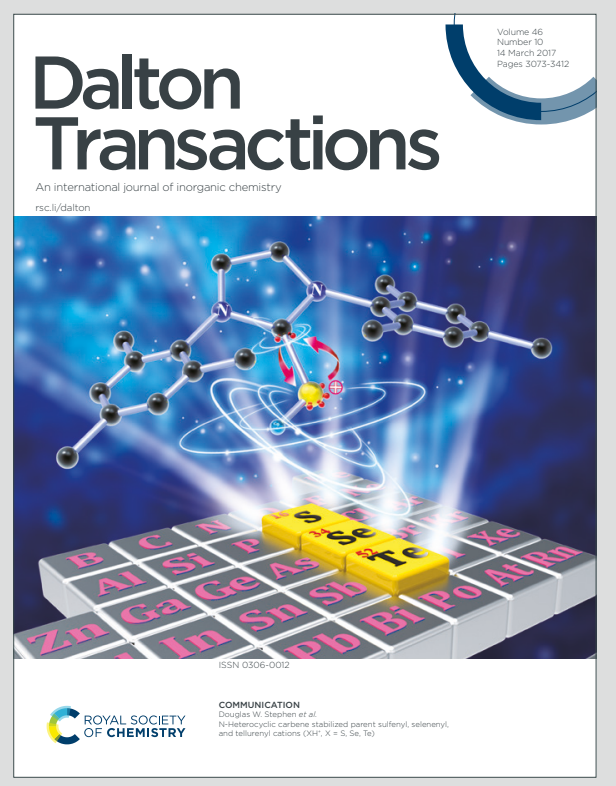

This is an Accepted Manuscript, which has been through the Royal Society of Chemistry peer review process and has been accepted for publication.

Accepted Manuscripts are published online shortly after acceptance, before technical editing, formatting and proof reading. Using this free service, authors can make their results available to the community, in citable form, before we publish the edited article. We will replace this Accepted Manuscript with the edited and formatted Advance Article as soon as it is available.

You can find more information about Accepted Manuscripts in the Information for Authors.

Please note that technical editing may introduce minor changes to the text and/or graphics, which may alter content. The journal's standard Terms \& Conditions and the Ethical guidelines still apply. In no event shall the Royal Society of Chemistry be held responsible for any errors or omissions in this Accepted Manuscript or any consequences arising from the use of any information it contains. 


\section{ARTICLETYPE}

Cite this: DOI: $00.0000 /$ xxxxxxxxxx

\section{Using Applied Pressure to Guide Materials Design: A Neutron Diffraction Study of $\mathrm{La}_{2} \mathrm{NiO}_{4+\delta}$ and $\mathrm{Pr}_{2} \mathrm{NiO}_{4+\delta} \delta^{\dagger}$}

\author{
Craig L. Bull, ${ }^{* a}$ Christopher J. Ridley, ${ }^{a}$ and Helen Y. Playford ${ }^{a}$
}

Received Date

Accepted Date

DOI: 00.0000/xxxxxxxxxx

\begin{abstract}
The compression behaviour of $\mathrm{La}_{2} \mathrm{NiO}_{4+\delta}$ and $\mathrm{Pr}_{2} \mathrm{NiO}_{4+\delta}$ have been studied up to a pressure of 2.8 and $2.2 \mathrm{GPa}$ respectively. Using neutron diffraction, the mechanism of compression, and the behaviour of the $\mathrm{NiO}_{6}$ and $\mathrm{La} / \mathrm{PrO}_{9}$ polyhedra in these layered perovskite materials have been determined. Their compression mechanisms have then been compared to related materials $\left(\mathrm{La}_{2-x} \mathrm{Pr}_{x} \mathrm{NiO}_{4}, \mathrm{Pr}_{2-x} \mathrm{Nd}_{x} \mathrm{NiO}_{4}, \mathrm{La}_{2-x} \mathrm{Sr}_{x} \mathrm{NiO}_{4}\right.$ and $\left.\mathrm{Pr}_{2-x} \mathrm{Ca}_{x} \mathrm{NiO}_{4}\right)$ where the unit-cell volume has been reduced by controlling the composition $(x)$, which acts as an 'effective chemical pressure'. Understanding the effects of both has implications for materials design; pressure can be used to finely tune a property, which theoretically may then be emulated using chemical doping.
\end{abstract}

\section{Introduction}

Perovskite-layered materials with the general formula $\mathrm{X}_{2} \mathrm{NiO}_{4}$ (where $\mathrm{X}=\mathrm{La}, \mathrm{Pr}, \mathrm{Nd}$ ) exhibit a number of interesting properties. ${ }^{1}$ For example $\mathrm{La}_{2} \mathrm{NiO}_{4}$ shows a temperature driven semiconductor to metal transition 23. The range of properties of related materials means that they find applications in intermediate temperature solid oxygen fuel cells (SOFC), as membranes for oxygen separation, ceramic oxygen generators and mixed-ionic electronic conductors. ${ }^{4}[6]$ The operational temperatures and efficiencies of such properties may be tuned by composition.

$\mathrm{The} \mathrm{La}_{2} \mathrm{NiO}_{4+\delta}$ perovskite-layered material crystallises in the $\mathrm{K}_{2} \mathrm{NiF}_{4}$ tetragonal structure $\mathrm{I} / \mathrm{mmm}$ (Figure 1) and can be viewed as perovskite like sheets of corner-shared octahedra which are separated along the $c$-axis by rock-salt like layers. ${ }^{7}$ The octahedral sheets contain the six-coordinated $\mathrm{Ni}$ - ions and the rock-saltlayers contain the nine-coordinate La atoms (in capped square anti-prism polyhedra, see Figure 11). Subtle distortions from this ideal tetragonal structure give rise to orthorhombic and monoclinic symmetries. For example, $\mathrm{Pr}_{2} \mathrm{NiO}_{4+\delta}$ crystallises in the related orthorhombic structure with space group Fmmm. Stoichiometric $\mathrm{La}_{2} \mathrm{NiO}_{4}$ is orthorhombic with space group $B m a b$ and, as previously mentioned, the oxygen excess material crystallises in the tetragonal symmetry with the general formula $\mathrm{La}_{2} \mathrm{NiO}_{4+\delta}$ with $\delta$ in the range $0.055-0.15 \cdot \frac{8}{8}$ In the tetragonal structure the La-atom is located on the $4 e$ Wyckoff site $(0,0, z)$ with $z \approx 0.36$, Ni on the $2 a$ Wyckoff site $(0,0,0), \mathrm{O}(1)$ on the $4 c$ Wyckoff site $\left(0, \frac{1}{2}, 0\right)$ and $\mathrm{O}(2)$ on the $4 e$ Wyckoff site with $z \approx 0.18$. In the orthorhom-

\footnotetext{
a ISIS Neutron and Muon Facility, STFC, Rutherford Appleton Laboratory, Chilton, OXON, OX11 OQX, U.K. Tel: + 441235 445706; *E-mail: craig.bull@stfc.ac.uk

$\dagger$ Electronic Supplementary Information (ESI) available: [Details of refined structural parameters as a function of pressure and RAW data]. See DOI: 10.5286/ISIS.E.RB1510598.
}

bic (Fmmm) structure the Pr-atom is located on the $8 i$ Wyckoff site $(0,0, z)$ with $z \approx 0.36$, Ni on the $4 a$ Wyckoff site $(0,0,0), \mathrm{O}(1)$ on the $8 e$ Wyckoff site $\left(\frac{1}{4}, \frac{1}{4}, 0\right)$ and $\mathrm{O}(2)$ on the $8 i$ Wyckoff site $(0,0, z)$ with $z \approx 0.17$. In both structures the displacement of the $\mathrm{O}(2)$ atom gives rise to a distorted $\mathrm{NiO}_{6}$ octahedron elongated in the $c$-direction with four shorter $\mathrm{Ni}-\mathrm{O}(1)$ bonds in the $a b$-plane and the two longer $\mathrm{Ni}-\mathrm{O}(2)$ bonds in the $c$-plane (Figure 1 ). The displacement of the $\mathrm{X}$-atom in the $z$-direction coupled with the $\mathrm{O}(2)$ atom displacement gives rise to a zig-zag arrangement of $\mathrm{O}(2)-\mathrm{X}-\mathrm{O}(2)$ bonds along the $a$ and $b$ directions (Figure 1 ).

Pressure is a powerful tool for accessing new physical properties while also affecting excited-state dynamics. High pressure provides a systematic control over interatomic distances in materials, a primary input for calculations of solid-state properties; high pressure studies also provide experimental support for theoretical models. High-pressure experiments can reveal desirable new properties and crystallographic structures and synthetic methods may then be developed to access these properties and structures at ambient pressure..$^{9} \mathrm{~A}$ methodology for doing this may employ the concept of 'chemical pressure', whereby ionic substitutions are used to induce similar distortions to the crystalline lattice.10111 Comparisons of chemical and hydrostatic pressure in systems have been previously made, for example in doped MnAs, $\mathrm{BaFe}_{2}\left(\mathrm{As}_{1-x} \mathrm{P}_{x}\right)_{2}, \mathrm{Gd}_{1-x} \mathrm{Y}_{x} \mathrm{Ba}_{2} \mathrm{Cu}_{3} \mathrm{O}_{7-\delta}, \mathrm{CoM}_{2} \mathrm{O}_{4}$ $(\mathrm{M}=\mathrm{Al}$, $\mathrm{Co}$ and $\mathrm{Rh}), \mathrm{SmNiC}_{2}$ and the bromido-bridged palladium compound $\left[\mathrm{Pd}(\mathrm{en})_{2} \mathrm{Br}\right]\left(\mathrm{Suc}_{-} \mathrm{C}_{n}\right)_{2} \cdot \mathrm{H}_{2} \mathrm{O} \cdot \underline{1012 \cdot 16}$ In the field of perovskite related materials the effects of changing the size of the central anion is used to replicate the effects of pressure and has been used to study the effects of magnetic interactions. For example, in ferrimagnetic materials $\mathrm{A}_{2} \mathrm{CrOsO}_{6}(\mathrm{~A}=\mathrm{Sr}, \mathrm{Ca}){ }^{17}$. Where there is a decreased interaction angle between $\mathrm{Cr}-\mathrm{O}-\mathrm{O}$ s when substituting $\mathrm{Ca}$ with $\mathrm{Sr}$ in the A-site and change in magnetic curie 

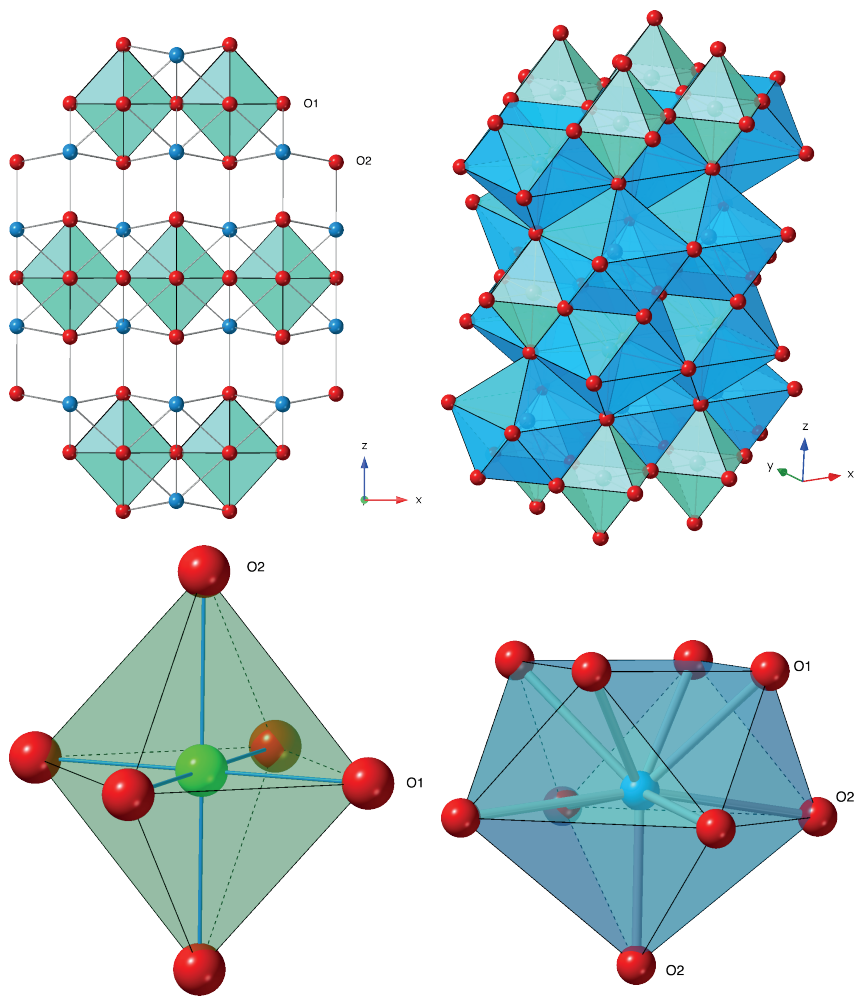

Fig. 1 Structure of the layered-perovskite $\mathrm{X}_{2} \mathrm{NiO}_{4}(\mathrm{X}=\mathrm{La}$ or $\mathrm{Pr})$. Top Left: overall structure looking down the $b$-axis. The $\mathrm{NiO}_{6}$ octahedra are shown as green polyhedra. The offset $\mathrm{O} 2$ and $\mathrm{X}$ atoms along the $c$-axis are clearly seen as a zig-zag across the structure. Top Right: The structure showing the $\mathrm{NiO}_{6}$ and $\mathrm{XO}_{9}$ polyhedra. The layers of $\mathrm{NiO}_{6}$ polyhedra and the interlaced $\mathrm{XO}_{9}$ polyhedra are clearly seen. Bottom Left: The $\mathrm{NiO}_{6}$ octahedra, the $\mathrm{O} 1$ atoms form the four shorter equal in-plane $\mathrm{Ni}-\mathrm{O}(1)$ bonds and the two $\mathrm{O} 2$ atoms form two longer $\mathrm{Ni}-\mathrm{O}(2)$ bonds in the $c^{-}$ direction, and give rise to a distortion of octahedra. Bottom Right: the capped-square anit-prism formed by nine non equal La-O bonds. In all figures the $X$ atoms are shown as a blue spheres, the nickel as a green spheres and oxygen as red spheres.

temperature. Another example would be the structural changes induced in the solid solution $\left(\mathrm{Sr}_{1-x} \mathrm{Ba}_{x}\right)_{2} \mathrm{FeSbO}_{6}$ which are shown to be analogous to that produced by hydrostatic pressure. ${ }^{18}$ The reduction in superconducting temperature in $\mathrm{K}_{2} \mathrm{NiF}_{4}$ structured $\mathrm{Sr}_{2} \mathrm{RuO}_{4}$ by hydrostatic pressure has also been mimicked by altering of the substrate on which the epitaxial thin films is grown.19

In the current study we have compressed tetragonal $\mathrm{La}_{2} \mathrm{NiO}_{4+\delta}$ and orthorhombic $\mathrm{Pr}_{2} \mathrm{NiO}_{4+\delta}$ up to pressures of 2.8 and $2.2 \mathrm{GPa}$ respectively at $300 \mathrm{~K}$. The crystallographic structure has been measured upon compression using neutron diffraction. We have then analysed the data to look at the behaviour of polyhedra in both materials with increasing pressure and these changes have then been compared to the behaviour of the polyhedra in related materials in order to quantify the chemical pressure due to doping.

\section{Experimental}

\subsection{Sample Synthesis}

To prepare $\mathrm{La}_{2} \mathrm{NiO}_{4}$ and $\mathrm{Pr}_{2} \mathrm{NiO}_{4}$, stoichiometric amounts of $\mathrm{La}\left(\mathrm{NO}_{3}\right)_{3} \cdot 6 \mathrm{H}_{2} \mathrm{O}, \quad \operatorname{Pr}\left(\mathrm{NO}_{3}\right)_{3} \cdot 6 \mathrm{H}_{2} \mathrm{O}$ and $\mathrm{Ni}\left(\mathrm{NO}_{3}\right)_{2} \cdot 6 \mathrm{H}_{2} \mathrm{O}$ (>99.99\%, Sigma-Aldrich) were dissolved in the minimum amount of distilled deionised water in an alumina crucible. The resulting solution was then warmed at $353 \mathrm{~K}$ to drive off the excess water and the temperature slowly increased to decompose the resulting gel. The resulting oxide mix was then sintered at $1373 \mathrm{~K}$ for $24 \mathrm{hr}$ in air and cooled slowly to ambient temperature, thoroughly ground, pelletised and annealed at the same temperature, until a single phase oxide resulted. X-ray diffraction was used to confirm phase purity, using a Rigaku Miniflex diffractometer with a filtered $\mathrm{Cu} \mathrm{K}_{\alpha 1,2}$ source over the range of $20-80^{\circ} 2 \theta$, with a step size of $0.05^{\circ}$.

\subsection{High-Pressure Neutron Diffraction}

Powdered sample was placed in an encapsulating null scattering TiZr gasket ${ }^{20}$ and sealed between a pair of zirconia-toughened alumina anvils within a V3 Paris-Edinburgh press 21 . To ensure hydrostatic conditions, perdeuterated methanol:ethanol (4:1 ratio by volume) was included in the sample chamber and small piece of lead included to act as a pressure marker. A sealing load of 6 tonnes was applied. The press was then mounted in the PEARL instrument at the ISIS Neutron and Muon Source in the $\mathrm{UK}^{22}$. A neutron powder time-of-flight (ToF) diffraction pattern was obtained in the $90^{\circ}$ scattering geometry giving access to a $d$-spacing range of $0.5-4 \AA$. Data sets were recorded for approximately 3 hours per pressure point, and data collected in 5 tonne increments up to a maximum applied load of 50 tonnes. The maximum pressure generated for each sample was $\sim 2.8$ and $2.8 \mathrm{GPa}$ for the $\mathrm{La}_{2} \mathrm{NiO}_{4}$ and $\mathrm{Pr}_{2} \mathrm{NiO}_{4}$ respectively, the differences being as a result of differing amounts of samples loaded in each experiment relative to the pressure transmitting medium. Data were focused, normalised and corrected for anvil attenuation using in-house software ${ }^{23}$ and Rietveld analysis performed using the GSAS suite of programmes 24 .

\section{Results and Discussion}

\subsection{High pressure behaviour of $\mathrm{La}_{2} \mathrm{NiO}_{4+\delta}$ and $\mathrm{Pr}_{2} \mathrm{NiO}_{4+\delta}$}

Figure 2 shows a representative neutron powder diffraction pattern of orthorhombic $\operatorname{Pr}_{2} \mathrm{NiO}_{4+\delta}(F m m m)$ at $2.2 \mathrm{GPa}$. Across the pressure range studied both $\mathrm{La}_{2} \mathrm{NiO}_{4+\delta}$ and $\mathrm{Pr}_{2} \mathrm{NiO}_{4+\delta}$ show no changes in symmetry, showing only a compression in unit-cell volume. For $\mathrm{La}_{2} \mathrm{NiO}_{4}$ with excess oxygen the published crystallographic structure includes an interstitial oxygen placed at the $4 d$ Wyckoff site $\left(0, \frac{1}{2}, \frac{1}{4}\right)$ with a low site occupancy $(\sim 0.1){ }^{25}$ However, in the current data addition of the above oxygen to the refinement results in no improvement in overall fit quality and the fractional occupancy and thermal motion when refined are highly correlated and we suggest this is a result of the attenuation of the data by the anvil and gasket material 26 , as such we have not included the excess oxygen in our subsequent refinements. Addition of the excess oxygen without fractional occupancy refine- 


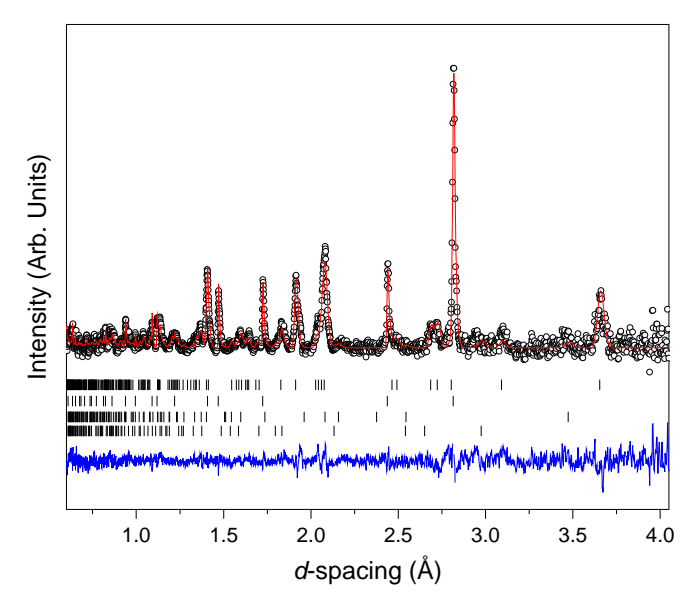

Fig. 2 Neutron powder diffraction pattern of $\mathrm{Pr}_{2} \mathrm{NiO}_{4+\delta}$ at $2.2 \mathrm{GPa}$. The raw data is shown as open black circles. Also shown by the red trace is the calculated profile of the Rietveld refinement of the data and the blue trace the residual of the fit to the data. The vertical tick marks show the positions of the Bragg reflections for the phases (from top to bottom, $\mathrm{Pr}_{2} \mathrm{NiO}_{4+\delta}, \mathrm{Pb}$ pressure marker, $\mathrm{ZrO}_{2}$ anvil and $\mathrm{Al}_{2} \mathrm{O}_{3}$ anvil).

ment resulted in no changes to the refined positions of $\mathrm{O}(1)$ and $\mathrm{O}(2)$ which are in agreement with those published previously. ${ }^{25}$

The compression behaviour of the tetragonal $\mathrm{La}_{2} \mathrm{NiO}_{4+\delta}$ and orthorhombic $\mathrm{Pr}_{2} \mathrm{NiO}_{4+\delta}$ unit-cell parameters is shown in Figure 3. The lattice parameters all show a decrease in value with increasing pressure. The individual lattice compressibilites for $\mathrm{La}_{2} \mathrm{NiO}_{4+\delta}$ have been determined as $k_{a}=k_{b}=2.1$ (4) $\mathrm{TPa}^{-1}$ and $k_{c}=2.37$ (9) $\mathrm{TPa}^{-1}$ and for $\mathrm{Pr}_{2} \mathrm{NiO}_{4+\delta}$ as $k_{a}=2.0(2), k_{b}=1.2(2) \mathrm{TPa}^{-1}$ and $k_{c}=3.5(2) \mathrm{TPa}^{-1}$. We note that the determination of the orthorhombic distortion may be limited by instrumental resolution, giving rise to the non-linear changes observed in the lattice parameters at low pressures, or there may be a subtle structural phase transition, however, we see no discontinuous behaviour in the unit-cell volume or anomalous behaviour in the bond distances beyond determined standard deviation. Figure 3 also shows the variation in unit-cell volume for $\mathrm{La}_{2} \mathrm{NiO}_{4+\delta}$ and $\mathrm{Pr}_{2} \mathrm{NiO}_{4+\delta}$ with increasing pressure which smoothly decreases in value upon compression. Also shown is the determined $2^{\text {nd }}$ order Birch-Murnaghan equation of state (EoS). A first-order phase transition (even an isosymmteric one) would result in discontinuous behaviour in unit-cell volume and would be clearly visible in the deviation of the unit-cell behaviour from the determined EoS. The difference in the bulk modulus between the two samples is small and the determined values of $\mathrm{B}_{0}$ are 147(1) GPa and 140(2) GPa for $\mathrm{La}_{2} \mathrm{NiO}_{4+\delta}$ and $\mathrm{Pr}_{2} \mathrm{NiO}_{4+\delta}$ respectively. These values are typical for oxide materials but are softer compared to the equivalent cuprate oxides $\mathrm{La}_{2} \mathrm{CuO}_{4}$ and $\mathrm{Pr}_{2} \mathrm{CuO}_{4}$ with values of 185 and $160 \mathrm{GPa}$ respectively. 27

For $\mathrm{La}_{2} \mathrm{NiO}_{4+\delta}$ the $\mathrm{Ni}-\mathrm{O}(1)$ bond length (Figure 4) which is found in the $a-b$ plane decreases with increasing pressure - given that the $a$ lattice parameter decreases linearly with increasing pressure with an estimated rate of change of $\sim$ -
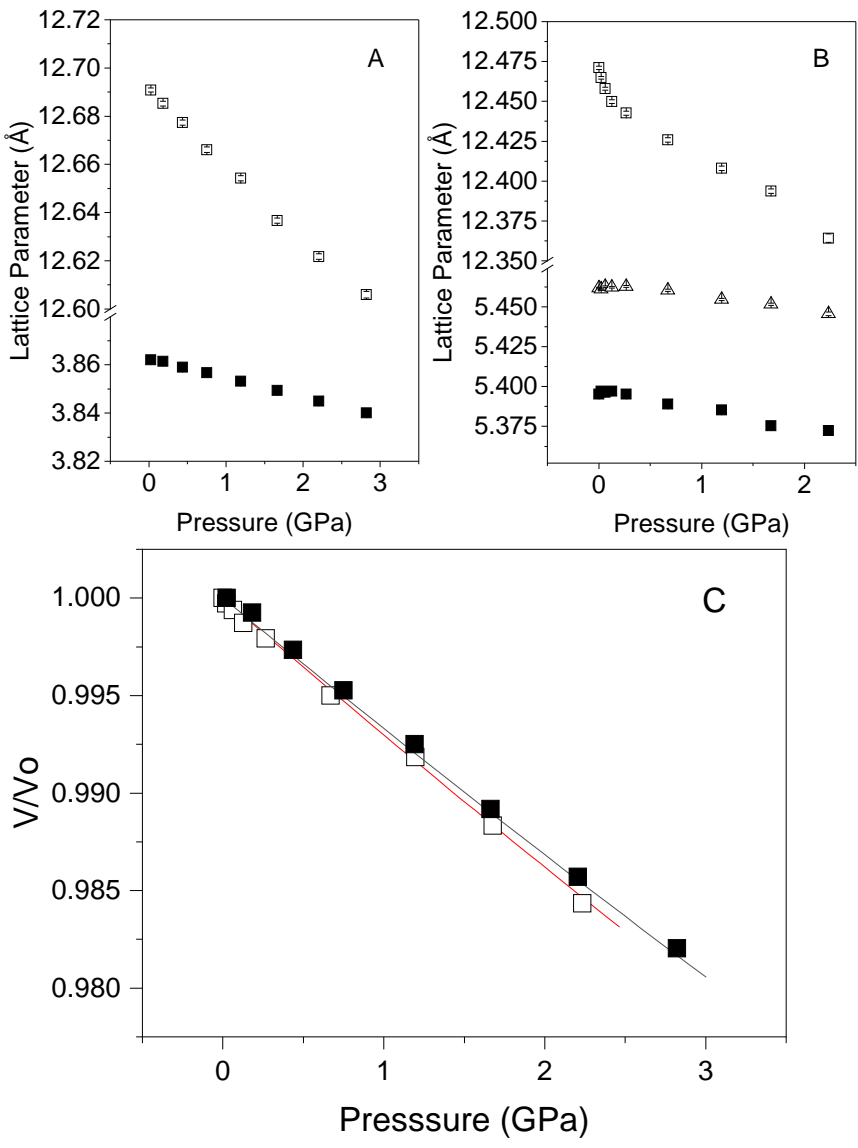

Fig. 3 Variation in unit-cell parameters with pressure for $\mathrm{La}_{2} \mathrm{NiO}_{4+\delta}$ and $\mathrm{Pr}_{2} \mathrm{NiO}_{4+\delta}$. A: Lattice parameters for tetragonal $\mathrm{La}_{2} \mathrm{NiO}_{4+\delta}, a=b$ shown as filled squares and the $c$ lattice parameter as open sqaures. B: Lattice parameters for orthorhombic $\mathrm{Pr}_{2} \mathrm{NiO}_{4+\delta}$, a as filled square, b by triangles, and $\mathrm{c}$ as open square. C: Variation of normalised (to ambient pressure $\mathrm{V}_{0}$ ) unit-cell volume (V) with pressure for $\mathrm{La}_{2} \mathrm{NiO}_{4+\delta}$ (filled square) and $\mathrm{Pr}_{2} \mathrm{NiO}_{4+\delta}$ (open square). The solid black trace shows the fit of a BirchMurhaghan equation of state to the $\mathrm{La}_{2} \mathrm{NiO}_{4+\delta}$ data and the red trace the equivalent for the $\mathrm{Pr}_{2} \mathrm{NiO}_{4+\delta}$ data. Error bars smaller than symbols. 
$0.004 \mathrm{AgPa}^{-1}$ (Figure 3). However, the Ni-O(2) bond length (which lies along the $c$-direction, Figure 11) increases with increasing pressure despite the $c$-axial length decreasing at the higher rate of $\sim 0.018 \mathrm{AGPa}^{-1}$. The ratio of $\mathrm{Ni}-\mathrm{O}(2) / \mathrm{Ni}-\mathrm{O}(1)$ bond length shows an overall trend of increasing with increasing pressure $\left(\sim 0.011 \mathrm{GPa}^{-1}\right)$. Deviations from an ideal value of 1 for the $\mathrm{Ni}-\mathrm{O}(2) / \mathrm{Ni}-\mathrm{O}(1)$ bond length ratio indicate distortion of the $\mathrm{NiO}_{6}$ octahedra and in the present case the trend suggests that these octahedra become increasingly distorted with increasing pressure, elongating along $z$. A different behaviour is observed for the Ni-O bonds in $\mathrm{Pr}_{2} \mathrm{NiO}_{4+\delta}$ where both bond lengths decrease with increasing pressure at a similar rate to each other $(\sim$ 0.003 and $-0.004 \AA_{\mathrm{GPa}^{-1}}$ for $\mathrm{Ni}-\mathrm{O}(1)$ and $\mathrm{Ni}-\mathrm{O}(2)$ respectively) and this overall results in a negligible increase in the $\mathrm{Ni}-\mathrm{O}(2) / \mathrm{Ni}-$ $\mathrm{O}(1)$ ratio with increasing pressure at a rate of $\sim 0.0007 \mathrm{GPa}^{-1}$ (Figure 4). The actual volume of the $\mathrm{NiO}_{6}$ octahedra in $\mathrm{La}_{2} \mathrm{NiO}_{4}$ shows a very small increase in size with increasing pressure $(\sim$ $0.04 \AA^{3} \mathrm{GPa}^{-1}$ ) and overall the compression is taken up by a reduction in volume of the distorted $\mathrm{LaO}_{9}$ polyhedra at a rate of $\sim-0.18 \AA^{3} \mathrm{GPa}^{-1}$ (Figure 4). For $\mathrm{Pr}_{2} \mathrm{NiO}_{4+\delta}$ both the $\mathrm{NiO}_{6}$ and $\mathrm{PrO}_{9}$ polyhedra decrease in volume at a rate of $\sim-0.05$ and $0.23 \AA^{3} \mathrm{GPa}^{-1}$ respectively (Figure 4). It therefore appears that there is a difference in the apparent compression mechanism between $\mathrm{La}_{2} \mathrm{NiO}_{4+\delta}$ and $\mathrm{Pr}_{2} \mathrm{NiO}_{4+\delta}$ where in both systems the $\mathrm{XO}_{9}$ polyhedra compress at a significantly faster rate compared to the slowly expanding $\mathrm{NiO}_{6}$ polyhedra in $\mathrm{La}_{2} \mathrm{NiO}_{4+\delta}$ and gradually compressing $\mathrm{NiO}_{6}$ octahedra in $\mathrm{Pr}_{2} \mathrm{NiO}_{4+\delta}$.

The point group of the octahedral $\left(\mathrm{NiO}_{6}\right)$ site is $D_{4 h}$. A shift of the oxygen atom along the $c$-axis leads to a stabilisation of the $d_{z^{2}}$ orbital with elongation of the $\mathrm{Ni}-\mathrm{O}(2)$ bond as is the case upon compression of $\mathrm{La}_{2} \mathrm{NiO}_{4+\delta}$ and a stabilisation of the $d_{x^{2}-y^{2}}$ orbital if the bond reduces in length as in the case of $\mathrm{Pr}_{2} \mathrm{NiO}_{4+\delta}$, with increasing pressure. .28 Such changes in orbital stabilisation would give rise to a change in covalency of the $\mathrm{Ni}-\mathrm{O}$ bonds in each direction as well of the $\mathrm{La} / \mathrm{Pr}-\mathrm{O}$ bonds.

There are three distinct $\mathrm{La}-\mathrm{O}$ bonds in the $\mathrm{LaO}_{9}$ polyhedra of the tetragonal $\mathrm{La}_{2} \mathrm{NiO}_{4+\delta}$. The longest four of which (La-O(2)) decrease in length with increasing pressure as does the shortest single $\mathrm{La}-\mathrm{O}(2)$ bond. However, the intermediate four $\mathrm{La}-\mathrm{O}(1)$ bonds display invariant behaviour with pressure within error. In orthorhombic $\mathrm{Pr}_{2} \mathrm{NiO}_{4+\delta}$ there are four distinct $\mathrm{Pr}-\mathrm{O}$ bonds in the $\mathrm{PrO}_{9}$ polyhedra and different behaviour is seen upon compression. The two longest $\mathrm{Pr}-\mathrm{O}(2)$ bond lengths are invariant at high pressure and the two slightly shorter $\mathrm{Pr}-\mathrm{O}(2)$ bond lengths decrease with increasing pressure. On average the single shortest $\mathrm{Pr}-\mathrm{O}(2)$ bond is invariant with increasing pressure and the intermediate four Pr-O(1) bonds decrease in length with increasing pressure (see S.I. $\dagger$ ).

There are no significant changes in the relative difference between the absolute bond valence sum to the formal oxidation state $\left(\left|\Delta V_{i}\right|\right)$ of the $\mathrm{NiO}_{6}$ octahedra in $\mathrm{La}_{2} \mathrm{NiO}_{4+\delta}$ and a small increase in $\mathrm{Pr}_{2} \mathrm{NiO}_{4+\delta}$ (Figure 4) with increasing pressure. ${ }^{29}$ There is however, a significant decrease in the difference in absolute bond valence sum of the $\mathrm{LaO}_{9}$ and $\mathrm{PrO}_{9}$ polyhedra at high pressure. It has been suggested that a difference in absolute bond valence sum greater than 0.1 is a result of strain in the bonds and hence for the $\mathrm{XO}_{9}$ capped square anti-prisms in the materials the strain is relieved with pressure, but there is no significant reduction in strain in the $\mathrm{NiO}_{6}$ polyhedra. ${ }^{30}$ However, given the oxygen excess it is hard to exactly quantify the absolute value of the bond valence sum. It is the mix of invariance and decrease in the $\mathrm{X}-\mathrm{O}$ bonds in the $\mathrm{XO}_{9}$ polyhedra in $\mathrm{La}_{2} \mathrm{NiO}_{4+\delta}$ and $\mathrm{Pr}_{2} \mathrm{NiO}_{4+\delta}$ which gives rise to the observed behaviour in difference in absolute bond valence sum. In previous studies, the oxidation state of $\mathrm{Pr}$ in $\mathrm{Pr}_{2} \mathrm{NiO}_{4+\delta}$ has been determined by XANES measurements to be $3+$, with the average oxidation state for nickel between $2+$ and $3+$. The latter was assumed to be $2+$ in the present bond valence sum calculations (but potentially could also be higher as a result of potential small quantities of oxide impurities below the detection limits of the techniques used). ${ }^{31}$ In the case of the Ni$\mathrm{O}$ bond valence for both materials we note the difference from $2+$ is quite high and suggests that the oxidation state is on average greater than $2+$ (as would be suggested by the oxygen excess described above). However, we are unable to confirm the exact value of the oxidation state of nickel, but no change in oxidation state would be expected to be induced with increasing pressure and the overall trends in the bond valence sum should be unaffected.

\subsection{Chemical vs Hydrostatic Pressure}

Having established the behaviour of the polyhedra in $\mathrm{La}_{2} \mathrm{NiO}_{4+\delta}$ and $\mathrm{Pr}_{2} \mathrm{NiO}_{4+\delta}$ with pressure we turn our attention to recreating the structural changes at ambient pressure. As previously discussed the concept of chemical pressure allows the recreation of the effects of hydrostatic pressure and for $\mathrm{La}_{2} \mathrm{NiO}_{4+\delta}$ and $\mathrm{Pr}_{2} \mathrm{NiO}_{4+\delta}$ doping of the lanthanide ion effectively changes the overall unit-cell volume.

Previous studies have shown a reasonably linear decrease in unit-cell volume with increasing chemical doping $(x)$ in the solid solutions $\mathrm{La}_{2-x} \mathrm{Pr}_{x} \mathrm{NiO}_{4}$ and $\mathrm{Pr}_{2-x} \mathrm{Nd}_{x} \mathrm{NiO}_{4}$ (see Figure 5). 32133 This is expected, as the ionic radii of the lanthanides decrease with increasing $Z$ across the lanthanide series La $(1.216 \AA)>\operatorname{Pr}$ $(1.179 \AA)>\mathrm{Nd}(1.163 \AA$ ) (with ninefold coordination in $3+$ oxidation state). It is possible to determine the equivalent pressure required to compress the parent (undoped) material to the same unit-cell volume using the EoS parameters determined for the end member. This is termed the 'effective chemical pressure'. 34 Figure 5 shows the determined pressure for each of the dopant levels using this method. The effective chemical pressure is different between the two systems for a given dopant level owing to the different EoS parameters for their respective end-members. The question remains however: do the polyhedra behave the same with effective chemical pressure as they do with hydrostatic pressure on the parent material?

Figure 6 shows the variation in polyhedral behaviour determined by previous studies 3233 of $\mathrm{La}_{2-x} \mathrm{Pr}_{x} \mathrm{NiO}_{4}$ and $\mathrm{Pr}_{2-x} \mathrm{Nd}_{x} \mathrm{NiO}_{4}$ replotted as a function of effective chemical pressure. Firstly, we look at the overall trends of the $\mathrm{Ni}-\mathrm{O}$ bonds within the $\mathrm{NiO}_{6}$ octahedra. For $\mathrm{La}_{2-x} \mathrm{Pr}_{x} \mathrm{NiO}_{4}$ the $\mathrm{Ni}-\mathrm{O}(1)$ bond decreases linearly with increasing effective chemical pressure, however the $\mathrm{Ni-O}(2)$ bond shows a small but reasonably lin- 

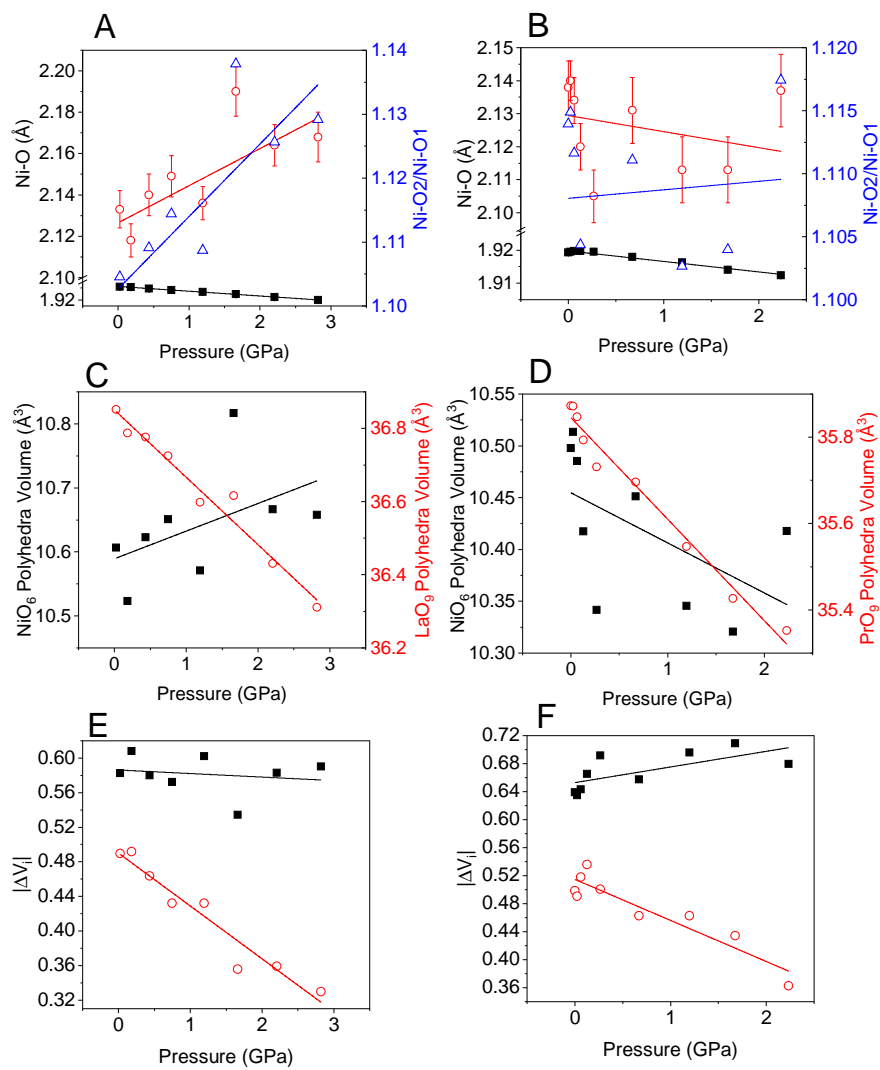

Fig. 4 Experimentally determined behaviour of polyhedra in $\mathrm{La}_{2} \mathrm{NiO}_{4+\delta}$ and $\mathrm{Pr}_{2} \mathrm{NiO}_{4+\delta}$ with pressure. $\mathrm{A} \& \mathrm{~B}$ : changes in $\mathrm{Ni}-\mathrm{O}(1)$ (squares) and $\mathrm{Ni}-\mathrm{O}(2)$ (circles) bond lengths for $\mathrm{La}_{2} \mathrm{NiO}_{4+\delta}(\mathrm{A})$ and $\mathrm{Pr}_{2} \mathrm{NiO}_{4+\delta}(\mathrm{B})$. The triangles show the variation in $\mathrm{Ni}-\mathrm{O}(2) / \mathrm{Ni}-\mathrm{O}(1)$ bond length ratios (propagated error bars smaller than symbols). C: Changes in $\mathrm{NiO}_{6}$ (squares) and $\mathrm{LaO}_{9}$ (circles) for $\mathrm{La}_{2} \mathrm{NiO}_{4+\delta}$. $\mathrm{D}$ : Changes in $\mathrm{NiO}_{6}$ (squares) and $\mathrm{PrO}_{9}$ (circles) for $\mathrm{Pr}_{2} \mathrm{NiO}_{4}$. E: Variation in bond valence difference for $\mathrm{NiO}_{6}$ (squares) and $\mathrm{LaO}_{9}$ polyhedra (circles) for $\mathrm{La}_{2} \mathrm{NiO}_{4+\delta}$. F: Variation in absolute bond valence sum difference for $\mathrm{NiO}_{6}$ (squares) and $\mathrm{PrO}_{9}$ polyhedra (circles) for $\mathrm{Pr}_{2} \mathrm{NiO}_{4+\delta}$. In all plots the solid lines are linear fit to the data points.

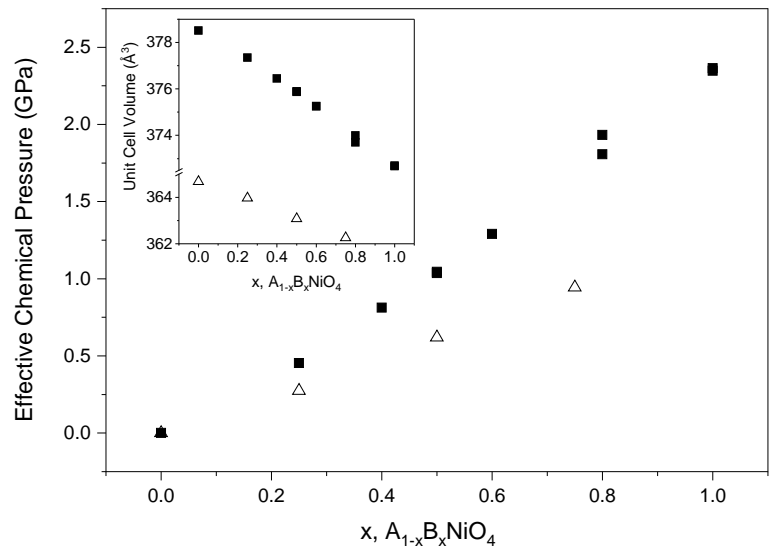

Fig. 5 Determined effective chemical pressure of $\mathrm{La}_{2-x} \mathrm{Pr}_{x} \mathrm{NiO}_{4}$ (square) and $\mathrm{Pr}_{2-x} \mathrm{Nd}_{x} \mathrm{NiO}_{4}$ (triangle) as a function of dopant concentration $x$. The inset shows the variation in experimentally determined unit-cell volume for $\mathrm{La}_{2-x} \mathrm{Pr}_{x} \mathrm{NiO}_{4}$ (square) and $\mathrm{Pr}_{2-x} \mathrm{Nd}_{x} \mathrm{NiO}_{4}$ (triangle). ${ }^{3233}$ For the $\mathrm{La}_{2-x} \mathrm{Pr}_{x} \mathrm{NiO}_{4}$ there are two values at high dopant levels as the sample was found to be mixed phase, with two different unit-cell volumes.

ear increase in effective chemical pressure. The same trend is seen in hydrostatic compression of $\mathrm{La}_{2} \mathrm{NiO}_{4+\delta}$ (Figure 4), and in both pressure regimes the distortion of the $\mathrm{NiO}_{6}$ octahedra increases. In $\mathrm{Pr}_{2-x} \mathrm{Nd}_{x} \mathrm{NiO}_{4}$ there is a change in behaviour of the $\mathrm{NiO}_{6}$ octahedra compared to that in $\mathrm{La}_{2-x} \mathrm{Pr}_{x} \mathrm{NiO}_{4}$ (Figure 6); unsurprisingly the $\mathrm{Ni}-\mathrm{O}(1)$ bonds decrease with increasing effective chemical pressure; the same trend is seen in the $\mathrm{Ni}-\mathrm{O}(2)$ bond, a decrease is also observed in the $\mathrm{Ni}-\mathrm{O}(2) / \mathrm{Ni}-\mathrm{O}(1)$ ratio. Upon the hydrostatic compression of $\mathrm{Pr}_{2} \mathrm{NiO}_{4+\delta}$ (Figure 4) both the Ni$\mathrm{O}(1)$ and $\mathrm{Ni}-\mathrm{O}(2)$ bond length on average decrease (albeit the $\mathrm{Ni}-\mathrm{O}(2)$ decreases at a significantly smaller rate); however, there is very little change in the $\mathrm{Ni}-\mathrm{O}(2) / \mathrm{Ni}-\mathrm{O}(1)$ ratio with increasing hydrostatic pressure, except on average a small increase.

Hydrostatic compression of $\mathrm{La}_{2} \mathrm{NiO}_{4+\delta}$ (Figure 4) results in a small (on average) increase in $\mathrm{NiO}_{6}$ polyhedral volume, but a measurable decrease in $\mathrm{LaO}_{9}$ polyhedral volume. The effect of chemical pressure on $\mathrm{La}_{2-x} \mathrm{Pr}_{x} \mathrm{NiO}_{4}$ results in a measurable decrease in both $\mathrm{NiO}_{6}$ and $\mathrm{La} / \mathrm{PrO}_{9}$ polyhedra, with the rate of decrease in $\mathrm{NiO}_{6}$ volume being less then that of the $\mathrm{La} / \mathrm{PrO}_{9}$ volume (Figure 6). Interestingly, the hydrostatic compression of $\mathrm{Pr}_{2} \mathrm{NiO}_{4+\delta}$ reduced the volume of both the $\mathrm{NiO}_{6}$ and $\mathrm{PrO}_{9}$ polyhedra, and the same behaviour is seen in the compression of $\mathrm{Pr}_{2-x} \mathrm{Nd}_{x} \mathrm{NiO}_{4}$ with effective chemical pressure.

The case described above is for a 'simple chemical pressure system' for which there is no change in oxidation state of the cations upon doping. However, it is possible to dope systems where the doping successively changes the average oxidation state of the ions. For example, in the case of $\mathrm{La}_{2-x} \mathrm{Sr}_{x} \mathrm{NiO}_{4}$ and $\mathrm{Pr}_{2-x} \mathrm{Ca}_{x} \mathrm{NiO}_{4}$ in which increasing $x$ reduces the unit-cell volume. $\frac{35 \mid 36}{36}$ The unitcell volumes converted to an effective chemical pressure are shown in Figure 77. However, the effective chemical pressure or reduction in unit-cell volume is not achieved by the same mechanism as described for the doping with atoms with the same oxidation state. Figure 7 shows the effective chemical pressure gen- 

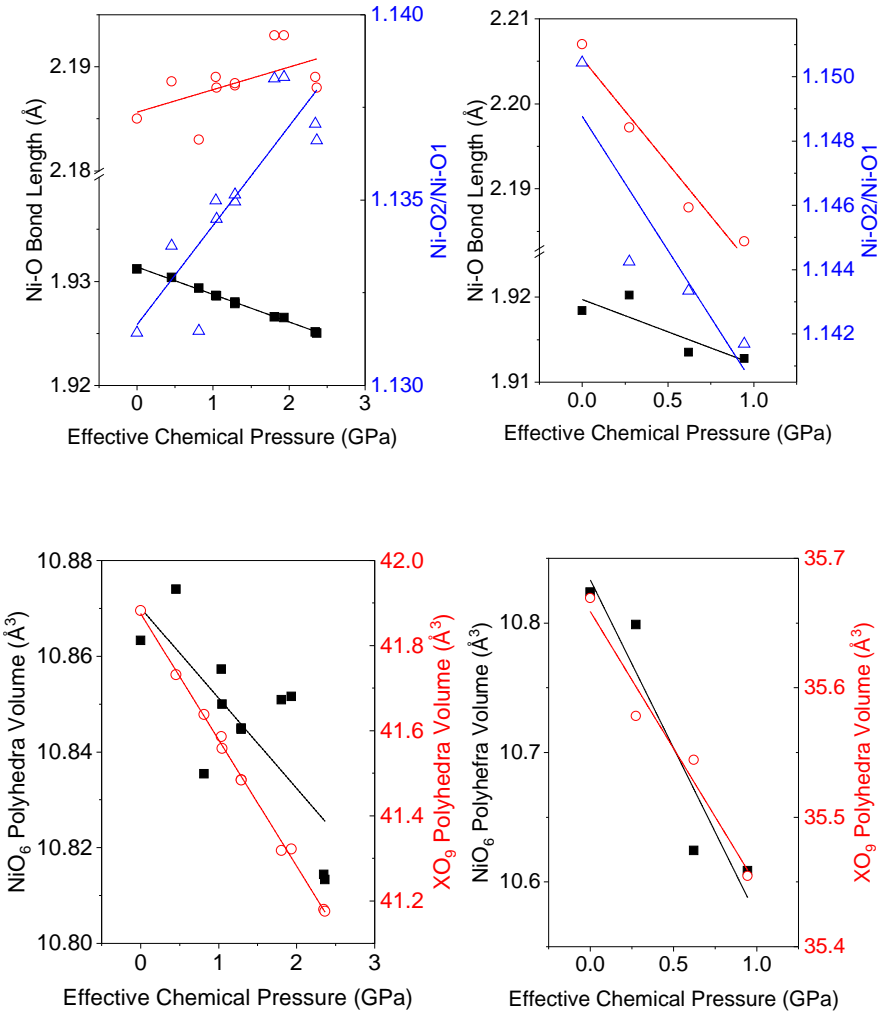

Fig. 6 Behaviour of polyhedra in $\mathrm{La}_{2-x} \mathrm{Pr}_{x} \mathrm{NiO}_{4}$ and $\mathrm{Pr}_{2-x} \mathrm{Nd}_{x} \mathrm{NiO}_{4}$ as a function of effective chemical pressure ${ }^{32 / 33}$. Top left: $\mathrm{NiO}_{6}$ octahedra in $\mathrm{La}_{2-x} \mathrm{Pr}_{x} \mathrm{NiO}_{4}$ as a function of effective chemical pressure, where the $\mathrm{Ni}-$ $\mathrm{O}(1)$ bond lengths shown as squares, $\mathrm{Ni}-\mathrm{O}(2)$ bond length as circles and the $\mathrm{Ni}-\mathrm{O}(2) / \mathrm{Ni}-\mathrm{O}(1)$ bond length ratio as triangles. Top Right: Variation in $\mathrm{NiO}_{6}$ octahedra in $\mathrm{Pr}_{2-x} \mathrm{Nd}_{x} \mathrm{NiO}_{4}$ as a function of effective chemical pressure, where the $\mathrm{Ni}-\mathrm{O}(1)$ bond length shown as squares, $\mathrm{Ni}-\mathrm{O}(2)$ bond length as circles and the $\mathrm{Ni}-\mathrm{O}(2) / \mathrm{Ni}-\mathrm{O}(1)$ bond length ratio as triangles. Bottom Left: Variation in $\mathrm{NiO}_{6}$ (squares) and $\mathrm{La} / \mathrm{PrO}_{9}$ (circles) polyhedra as a function of effective chemical pressure for $\mathrm{Pr}_{2-x} \mathrm{Nd}_{x} \mathrm{NiO}_{4}$. Bottom Right: Variation in $\mathrm{NiO}_{6}$ (squares) and $\mathrm{Pr} / \mathrm{NdO}_{9}$ (circles) polyhedra as a function of effective chemical pressure for $\mathrm{Pr}_{2-x} \mathrm{Nd}_{x} \mathrm{NiO}_{4}$. erated for the average atomic radius of the $\mathrm{X}$ atom in $\mathrm{X}_{2} \mathrm{NiO}_{4}$ which changes with doping (it is assumed that the Pr ion remains in the $3+$ oxidation state although some studies show that for similar materials some $\mathrm{Pr}^{4+}$ may be present with doping ${ }^{37}$ ). For the systems where $\mathrm{X}=\mathrm{La}_{2-x} \mathrm{Pr}_{x}$ and $\operatorname{Pr}_{2-x} \mathrm{Nd}_{x}$ the average atomic radius decreases with increasing dopant $x$ (or effective chemical pressure) however, for the system $\mathrm{La}_{2-x} \mathrm{Sr}_{x}$ and $\operatorname{Pr}_{2-x} \mathrm{Ca}_{x}$ the average atomic radius increase (albeit at different rates) despite a decrease in unit-cell volume or an increase in effective chemical pressure. The successive doping with $2+(\mathrm{Ca} / \mathrm{Sr})$ cations means that the average oxidation state of the nickel ion has to change to compensate and as such it increases from $2+$ with increasing level of dopant $(x)$.

In $\mathrm{Pr}_{2-x} \mathrm{Ca}_{x} \mathrm{NiO}_{4}$ there is a decrease in both the $\mathrm{Ni}-\mathrm{O}(1)$ and $\mathrm{Ni}-\mathrm{O}(2)$ bond lengths (see Figure 7) and replicated in the hydrostatic compression of $\mathrm{Pr}_{2} \mathrm{NiO}_{4+\delta}$. However, the difference in rate of change leads to an overall increase in $\mathrm{Ni-O}(2) / \mathrm{Ni}-\mathrm{O}(1)$ bond length ratio and hence an increase in distortion of the octahedra. In comparison the hydrostatic compression, the rate of change in the $\mathrm{Ni}-\mathrm{O}(2)$ and $\mathrm{Ni}-\mathrm{O}(1)$ bonds gives very little change in the distortion of the octahedra. In $\mathrm{La}_{2-x} \mathrm{Sr}_{x} \mathrm{NiO}_{4}$ there is a decrease again in $\mathrm{Ni}-\mathrm{O}(1)$ and $\mathrm{Ni-O}(2)$ bond lengths (see Figure 77) but the rates of which give rise to an overall decrease in the $\mathrm{Ni}-\mathrm{O}(2) / \mathrm{Ni}-\mathrm{O}(1)$ bond length ratio (and hence less polyhedral distortion/strain) and is opposite to the hydrostatic compression of $\mathrm{La}_{2} \mathrm{NiO}_{4+\delta}$. In both systems there is a decrease in the $\mathrm{NiO}_{6}$ and $\mathrm{XO}_{9}$ polyhedral volume with increasing effective chemical pressure, which is in contrast to the situation seen for the hydrostatic compression of $\mathrm{La}_{2} \mathrm{NiO}_{4+\delta}$ but the same as $\mathrm{Pr}_{2} \mathrm{NiO}_{4+\delta}$, although the behaviour in the doping with $2+$ ions means that complications arise in behaviour of the $\mathrm{X}$ and $\mathrm{Ni}$ ions due to changes in oxidation states and this is difficult to disentangle from a simple change in the average ionic radius of the $\mathrm{X}$ atom.

\section{Conclusions}

We have shown how tetragonal $\mathrm{La}_{2} \mathrm{NiO}_{4+\delta}$ and orthorhombic $\mathrm{Pr}_{2} \mathrm{NiO}_{4+\delta}$ compress upon application of hydrostatic pressure up to $\sim 2.5 \mathrm{GPa}$. The mechanism of compression differs slightly between the two layered perovskite materials in the way the $\mathrm{NiO}_{6}$ octahedra and $\mathrm{La} / \mathrm{PrO}_{9}$ polyhedra behave. This behaviour has then been compared to the effective chemical pressure induced reduction in unit-cell volume for $\mathrm{La}_{2-x} \mathrm{Pr}_{x} \mathrm{NiO}_{4}, \mathrm{Pr}_{2-x} \mathrm{Nd}_{x} \mathrm{NiO}_{4}$, $\mathrm{La}_{2-x} \mathrm{Sr}_{x} \mathrm{NiO}_{4}$ and $\mathrm{Pr}_{2-x} \mathrm{Ca}_{x} \mathrm{NiO}_{4}$. The study shows that application of hydrostatic pressure to a parent compound overall is reasonably able to predict the effects of chemical pressure in this series of materials however, the effects of changes in oxidation states of the cations needs to be taken into consideration. For further studies to make use of this methodology, the bulk modulus of the chemically doped material has to be similar to the material studied at high pressure, however, there is a growing number of high pressure crystallographic studies for which suitable comparisons can be made and increasing ease of access to facilities for performing suitable high-pressure studies. This study starts to show that it may be possible in the right chemical system to use experimental in situ physical pressure measurements to guide synthetic routes to new materials with suitable physical or struc- 

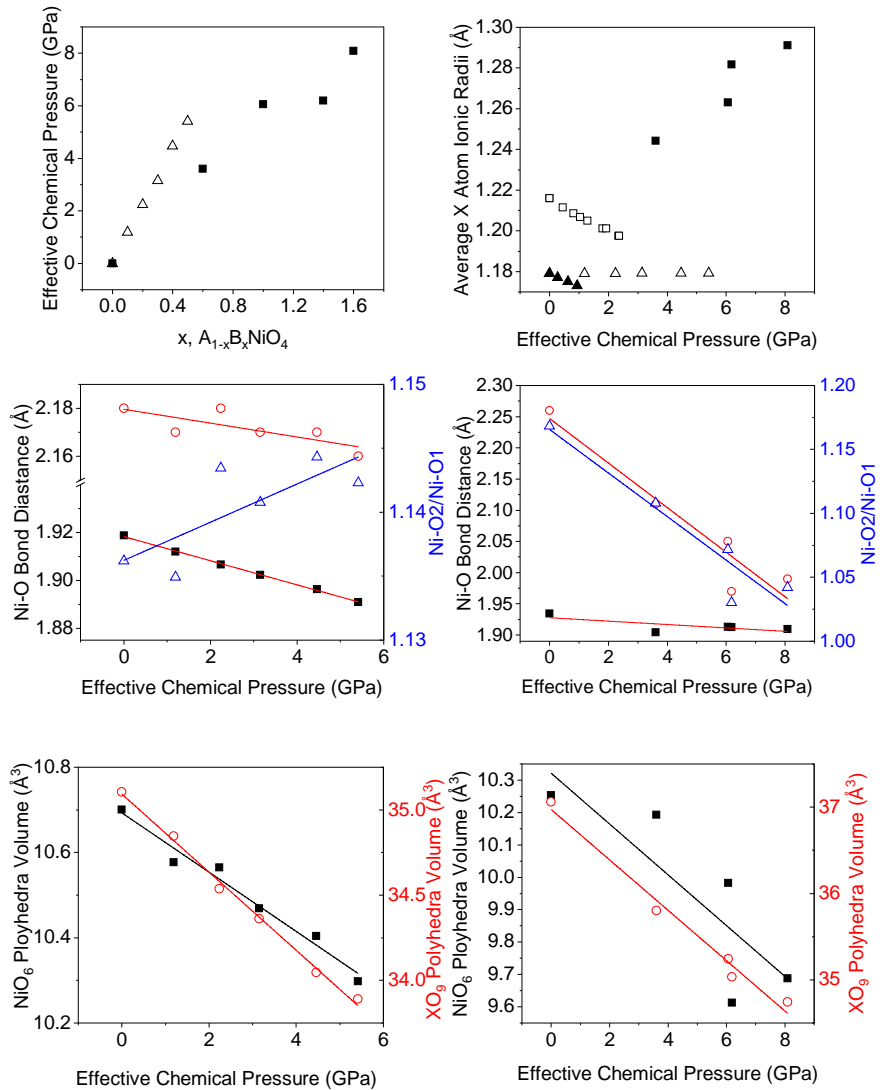

Fig. 7 Behaviour of polyhedra in $\mathrm{La}_{2-x} \mathrm{Sr}_{x} \mathrm{NiO}_{4}$ and $\mathrm{Pr}_{2-x} \mathrm{Ca}_{x} \mathrm{NiO}_{4}$ as a function of effective chemical pressure based upon previous published results. $.35 \mid 36$ Top left: determined effective chemical pressure of $\mathrm{La}_{2-x} \mathrm{Sr}_{x} \mathrm{NiO}_{4}$ and $\mathrm{Pr}_{2-x} \mathrm{Ca}_{x} \mathrm{NiO}_{4}$ as a function of level of dopant $x$. Top Right: Average ionic radius of $\mathrm{A}$ and $\mathrm{B}$ atoms $(\mathrm{X})$ in $\mathrm{A}_{2-x} \mathrm{~B}_{x} \mathrm{NiO}_{4}, \mathrm{La}_{2-x} \mathrm{Sr}_{x} \mathrm{NiO}_{4}$ shown by squares, $\mathrm{Pr}_{2-x} \mathrm{Ca}_{x} \mathrm{NiO}_{4}$ by triangles, $\mathrm{La}_{2-x} \mathrm{Pr}_{x} \mathrm{NiO}_{4}$ by squares and $\mathrm{Pr}_{2-x} \mathrm{Nd}_{x} \mathrm{NiO}_{4}$ by triangles. Middle Left: Variation in $\mathrm{NiO}_{6}$ octahedra in $\mathrm{Pr}_{2-x} \mathrm{Ca}_{x} \mathrm{NiO}_{4}$ as a function of effective chemical pressure, $\mathrm{Ni}-\mathrm{O}(1)$ bond length shown as squares, $\mathrm{Ni}-\mathrm{O}(2)$ bond length as circles and the $\mathrm{Ni}-\mathrm{O}(2) / \mathrm{Ni}-\mathrm{O}(1)$ bond length ratio as triangles. Middle Right: Variation in $\mathrm{NiO}_{6}$ octahedra in $\mathrm{La}_{2-x} \mathrm{Sr}_{x} \mathrm{NiO}_{4}$ as a function of effective chemical pressure, the $\mathrm{Ni}-\mathrm{O}(1)$ bond length shown as squares, $\mathrm{Ni}-\mathrm{O}(2)$ bond length as circles and the $\mathrm{Ni}-\mathrm{O}(2) / \mathrm{Ni}-\mathrm{O}(1)$ bond length ratio as triangles. Bottom Left: Variation in $\mathrm{NiO}_{6}$ (squares) and $\mathrm{Pr} / \mathrm{CaO}_{9}$ (circles) polyhedra as a function of effective chemical pressure for $\mathrm{Pr}_{2-x} \mathrm{Ca}_{x} \mathrm{NiO}_{4}$. Bottom Right: Variation in $\mathrm{NiO}_{6}$ (squares) and $\mathrm{La} / \mathrm{SrO}_{9}$ (circles) polyhedra as a function of effective chemical pressure for $\mathrm{La}_{2-x} \mathrm{Sr}_{x} \mathrm{NiO}_{4}$. tural properties.

\section{Conflicts of interest}

There are no conflicts to declare.

\section{Acknowledgements}

The authors thank STFC for providing access to the PEARL instrument. $\frac{38}{38}$ The authors also thank Kevin Knight (Dept of Earth Sciences, UCL) for his helpful comments on the manuscript as a whole.

\section{Notes and references}

1 A. Flura, S. Dru, C. Nicollet, V. Vibhu, S. Fourcade, E. Lebraud, A. Rougier, J.-M. Bassat and J.-C. Grenier, Journal of Solid State Chemistry, 2015, 228, 189 - 198.

2 N. Zhou, G. Chen, H. J. Zhang and C. Zhou, Physica B: Condensed Matter, 2009, 404, 4150 - 4154.

3 D. ping Huang, Q. Xu, F. Zhang, W. Chen, H. xing Liu and J. Zhou, Materials Letters, 2006, 60, 1892 - 1895.

4 V. V. Vashook, I. I. Yushkevich, L. V. Kokhanovsky, L. V. Makhnach, S. P. Tolochko, I. F. Kononyuk, H. Ullmann and H. Altenburg, Solid State Ionics, 1999, 119, 23 - 30.

5 S. J. Skinner and J. A. Kilner, Solid State Ionics, 2000, 135, $709-712$.

6 J. B. Smith and T. Norby, Journal of The Electrochemical Society, 2006, 153, A233.

7 J. F. Ackerman, Materials Research Bulletin, 1979, 14, 487 491.

8 H. Tamura, A. Hayashi and Y. Ueda, Physica C: Superconductivity, 1993, 216, 83 - 88.

9 A. Jaffe, Y. Lin and H. I. Karunadasa, ACS Energy Letters, 2017, 2, 1549-1555.

10 A. A. R. Fernandes, J. Santamaria, S. L. Bud'ko, O. Nakamura, J. Guimpel and I. K. Schuller, Phys. Rev. B, 1991, 44, 76017606.

11 A. Hauser, N. Amstutz, S. Delahaye, A. Sadki, S. Schenker, R. Sieber and M. Zerara, CHIMIA International Journal for Chemistry, 2002, 56, 685-689.

12 A. Zięba and R. Zach and H. Fjellvåg and A. Kjekshus, Journal of Physics and Chemistry of Solids, 1987, 48, $79-89$.

13 L. E. Klintberg, S. K. Goh, S. Kasahara, Y. Nakai, K. Ishida, M. Sutherland, T. Shibauchi, Y. Matsuda and T. Terashima, Journal of the Physical Society of Japan, 2010, 79, 123706.

14 T. Naka, J. Valenta, J. Kaštil, M. Míšek, J. Prchal, V. Sechovský, H. Abe, T. Nakane, M. Nakayama and T. Uchikoshi, Materials Research Express, 2020, 7, 056105.

15 J. N. Kim, C. Lee and J.-H. Shim, New Journal of Physics, 2013, 15, 123018.

16 S. Kumagai, S. Takaishi, H. Iguchi, B. K. Breedlove, T. Kaneko, H. Ito, S.-i. Kuroda and M. Yamashita, Inorganic Chemistry, 2018, 57, 12-15.

17 R. Morrow, J. R. Soliz, A. J. Hauser, J. C. Gallagher, M. A. Susner, M. D. Sumption, A. A. Aczel, J. Yan, F. Yang and P. M. Woodward, Journal of Solid State Chemistry, 2016, 238, 46 - 
52.

18 T. Tiittanen and M. Karppinen, Journal of Solid State Chemistry, 2017, 246, 245 - 251.

19 D. G. Schlom, Y. Jia, L. N. Zou, J. H. Hanei, S. Briczinski, M. A. Zurbuchen, C. W. Leitz, S. Madhavan, S. Wozniak, Y. Liu, M. E. Hawley, G. W. Brown, A. Dabkowski, H. A. Dabkowska, R. Uecker and P. Reiche, Superconducting and Related Oxides: Physics and Nanoengineering III, 1998, 3481, 226 - 240.

20 W. G. Marshall and D. J. Francis, Journal of Applied Crystallography, 2002, 35, 122-125.

21 J. M. Besson, R. J. Nelmes, G. Hamel, J. S. Loveday, G. Weill and S. Hull, Physica B, 1992, 180, 907-910.

22 C. L. Bull, N. P. Funnell, M. G. Tucker, S. Hull, D. J. Francis and W. G. Marshall, High Pressure Res., 2016, 36, 493-511.

23 O. Arnold, J. C. Bilheux, J. M. Borreguero, A. Buts, S. I. Campbell, L. Chapon, M. Doucet, N. Draper, R. Ferraz Leal, M. A. Gigg, V. E. Lynch, A. Markvardsen, D. J. Mikkelson, R. L. Mikkelson, R. Miller, K. Palmen, P. Parker, G. Passos, T. G. Perring, P. F. Peterson, S. Ren, M. A. Reuter, A. T. Savici, J. W. Taylor, R. J. Taylor, R. Tolchenov, W. Zhou and J. Zikovsky, Nucl. Instrum. Meth. A, 2014, 764, 156-166.

24 B. H. Toby, J. Appl. Crystallogr., 2001, 34, 210-213.

25 F. Serrano-Sánchez, R. Pinacca, L. Troncoso, N. Nemes, J. Martínez and J. Alonso, Materials Today: Proceedings, 2018, 5, 10203 - 10210.

26 R. Wilson, J. Loveday, R. Nelmes, S. Klotz and W. Marshall, Nuclear Instruments and Methods in Physics Research Section A: Accelerators, Spectrometers, Detectors and Associated Equipment, 1995, 354, 145 - 148.

27 W. Fietz, C. Wassilew, D. Ewert, M. Dietrich, H. Wühl, D. Hochheimer and Z. Fisk, Physics Letters A, 1989, 142, 300 -306 .

28 G. Le Flem, G. Dmazeau and P. Hagenmuller, Journal of Solid State Chemistry, 1982, 44, 82 - 88.

29 I. D. Brown and D. Altermatt, Acta Crystallographica Section B, 1985, 41, 244-247.

30 J. Zhao, N. L. Ross and R. J. Angel, Acta Crystallographica Section B, 2004, 60, 263-271.

31 T. Ogier, C. Prestipino, S. Figueroa, F. Mauvy, J. Mougin, J. C. Grenier, A. Demourgues and J. M. Bassat, Chemical Physics Letters, 2019, 727, 116 - 120.

32 E. Dogdibegovic, Q. Cai, N. S. Alabri, W. Guan and X.-D. Zhou, Journal of The Electrochemical Society, 2016, 164, F99-F106.

33 V. Vibhu, M. R. Suchomel, N. Penin, F. Weill, J.-C. Grenier, J.M. Bassat and A. Rougier, Dalton Trans., 2019, 48, 266-277.

34 F. Cocks and H. M. Hammarstrom, Materials Chemistry and Physics, 1994, 36, 343 - 349.

35 Y. Takeda, R. Kanno, M. Sakano, O. Yamamoto, M. Takano, Y. Bando, H. Akinaga, K. Takita and J. B. Goodenough, Materials Research Bulletin, 1990, 25, 293 - 306.

36 V. A. Sadykov, E. Y. Pikalova, A. A. Kolchugin, E. A. Filonova, E. M. Sadovskaya, N. F. Eremeev, A. V. Ishchenko, A. V. Fetisov and S. M. Pikalov, Solid State Ionics, 2018, 317, 234 - 243.

37 Z. Tan, S. M. Heald, S.-W. Cheong, A. S. Cooper and J. I.
Budnick, Phys. Rev. B, 1992, 45, 2593-2596.

38 C. L. Bull, STFC ISIS Facility, 2015, https://doi.org/10.5286/ISIS.E.RB1510598. 


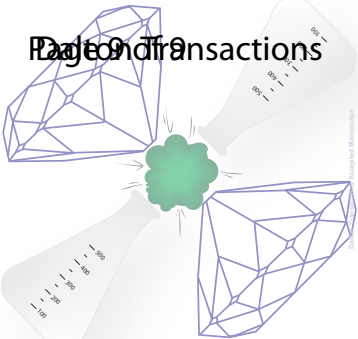

High-pressure structural changes being used as a guide to materials design 